\title{
Obtención de polihidroxialcanoatos (PHA) a partir de cultivos mixtos microbianos usando efluentes ricos en ácidos grasos volátiles como sustrato
}

\author{
Mixed culture Polyhydroxyalkanoate obtention (PHA) from volatile fatty acid rich stream as a \\ sustrate
}

\author{
Rolando Calero Mendoza \\ Departamento de Ingeniería Química \\ Facultad de Ciencias \\ Universidad de la Coruña (UDC) \\ Rúa da Fraga, 10, 15008 A Coruña -España \\ r.calero@udc.es
}

\begin{abstract}
Resumen
La finalidad de este trabajo consiste en el estudio de bioreactores en la obtención de biopolímeros (polihidroxialkanoatos) de fuentes mixtas microbianas utilizando sueros de quesería de la industria láctea como sustrato. Para obtener polihidroxialcanoatos (PHAs) primero se partió de un proceso de enriquecimiento de la cepa bacteriana en un reactor aerobio secuencial (SBR) donde la flora microbiana se somete a un proceso de selección para poder alcanzar los máximos niveles de reserva del polímero. El sustrato utilizado es mayoritariamente ácidos grasos volátiles o de cadena corta obtenido en una etapa preliminar de tratamiento en un reactor anaerobio en donde el contenido de azucares del suero lácteo es sometido a un proceso de fermentación. Una vez enriquecida la flora bacteriana se estudia la producción de PHAs producido en otro reactor llamado reactor de alimentación. En este experimento se muestra la capacidad de producción de PHA que alcanza el 42 \% en comparación a la biomasa activa del lodo residual.
\end{abstract}

Palabras Claves: Bioreactores, Bioplásticos, Cultivos mixtos, Polihidroxialcanoato, Ácidos grasos volátiles. (5)

\begin{abstract}
The aim of this work is about the study of bioreactors in obtaining biopolymers (polyhydroxyalkanoate) by mixed microbial sources using cheese whey from the dairy industry as a substrate. To obtain polyhydroxyalkanoates (PHAs) is necessary to start with an enrichment process of the bacterial strain in a sequential batch reactor (SBR) where the microbial culture is subjected to a selection process in order to achieve the highest levels of polymer reserve. The substrate used is mainly compound of volatile short chain fatty obtained in a preliminary stage of treatment in an anaerobic reactor wherein the sugar content of the whey is subjected to a process of acids fermentation. Once enriched the bacterial cultures with great capacity of storage of PHAs, we proceed in other reactor process known as a FedBatch in order to obtain a maximum production of biopolymer. In this experiment the PHA obtaining was about $42 \%$ compared with the activate biomass.
\end{abstract}

Keywords: Bioreactor, Bioplastic, mixed culture, Polyhydroxyalkanoate, Volatile fat acid. 


\section{Introducción}

Los Polihidroxialcanoatos (PHAs) son polímeros producidos naturalmente por diferentes tipos de bacterias como reservas naturales de carbono y energía. El más abundantes PHAs encontrado es el homopolímero poli(3-hidroxibutirato) (PHB). Los PHA han llamado el interés como bioplástico debido a que estos exhiben propiedades termoplásticas y elastómeras, son enantiomericamente puros es decir producen R-estero isómeros, no son tóxicos, son biocompatibles, son obtenidos de reservas renovables y son biodegradables. Además estos polímeros pueden ser hidrolizados dando como productos monómeros de hidroxi ácidos grasos que pueden servir como elementos para la producción de bioquímicos.

Algunas de estas bacterias estudiadas pueden acumular PHAs hasta de un $70 \%$ a un $90 \%$ de su peso seco. Actualmente la producción comercial de PHA se basa en bacterias genéticamente aplicadas a este proceso capaces de producir hasta $100 \mathrm{~g} / \mathrm{L}$ de PHA en 40 h o menos usando sustratos puros como azúcar alcanzando en estos casos hasta un 90\% de PHA del contenido celular.

Generalmente para alcanzar estos objetivos en estos procesos biotecnológicos se emplean cultivos puros además de bien establecidas condiciones de alimentación y de condiciones asépticas adecuadas. Por lo que esto hace que el proceso tenga un alto costo ya sea por el alto costo del sustrato como por el alto costo de los equipos y el alto consumo de energía provocando en definitiva condiciones desfavorables para una producción a gran escala que pueda competir con la industria de plástico convencional.

Una tentativa alternativa para la producción sostenible de bioplásticos es la utilización de cultivos mixtos microbianos en lo que se conoce como ecobiotecnología que no es otra cosa que producir productos biotecnológicos empleando cultivos mixtos abiertos utilizando principios de selección natural; de esta forma se combina metodología de biotecnología ambiental con los propósitos de la biotecnología industrial.

Hasta ahora los cultivos mixtos han sido solo aplicados en el tratamiento de residuos (tratamiento biológico en plantas de tratamiento de aguas de residuo) y parcialmente para la producción de biogás, en la bio-hidrometalurgia o en procesos tradicionales de fermentación de alimentos, pero no en la producción de bioquímicos o biomateriales.

El principio de la eco-biotecnologia está basada en la selección natural y competencia más que en la ingeniería genética o metabólica de las cepas bacterianas.
La presión selectiva para un metabolismo deseado es aplicado a un inoculo, escogiendo el sustrato adecuado y operando en bio-reactores en condiciones que favorezcan la supervivencia de los que mayoritariamente puedan almacenar la mayor cantidad de reserva de PHA en su organismo.

Estas condiciones están delimitadas al sustrato empleado, al $\mathrm{pH}$, la temperatura, y por sobre todo de las condiciones dinámicas de un ciclo de alimentación y reposo empleado, el tiempo de alimentación es el tiempo en que las cepas se alimentan del sustrato, y transforman el alimento en reservas de polihidroxialcanoato; y el tiempo de reposo es el tiempo en que las cepas bacterianas no obtienen alimentos del exterior y utilizan las reservas de PHAs para alimentarse y crecer.

El sustrato empleado es muy importante ya que debe proveer la materia prima necesaria para transformarlo en reservas de PHAs. Estos sustratos generalmente son fuentes de azucares y productos fermentados de estos como pueden ser los ácidos grasos volátiles o de cadena corta.

Como generalmente se tiene que realizar un proceso de fermentación de azucares, se debe utilizar reactores de digestión anaerobia para este propósito, transformando los azucares de las aguas de tratamiento de industrias alimenticias, en ácidos grasos volátiles teniendo cuidado de las condiciones en que se desarrollan porque podrían dar lugar al desarrollo de cepas bacterianas distintas que favorezcan la metanogénesis del sustrato.

La producción de PHA en cultivos mixtos ha sido estudiada en el pasado mayoritariamente debido a su importancia en el tratamiento de aguas de residuos más que por su potencial proceso de producción. Actualmente las investigaciones en esta área están orientado en el uso de efluentes líquidos proveniente de industrias alimenticias como el aceite de oliva, aceite de palma, melazas de caña de azúcar, industria del papel cervecería, y de la industria láctea. La optimización de la producción de PHA por cultivos mixtos ha llegado a producir hasta un 65\% de PHB de su contenido seco utilizando acetato como sustrato. Sin embargo este porcentaje es aún bajo comparado con los utilizados en la industria que utilizan cultivos puros, y requiere mejoras para la optimización del proceso.

El propósito de este estudio es mostrar el uso de sustrato provenientes de suero de quesería puede ser un recurso valorable en la producción a gran escala de PHA, utilizando cultivos mixtos microbianos. Para lo cual se deberá utilizar un proceso de tres pasos (i) fermentación en un bioreactor anerobio del efluente proveniente de suero de quesería (ii) enriquecimiento y crecimiento de bacterias mixtas productoras de PHA 
y (iii) producción de PHA al maximizar el contenido celular de PHA al recolectar la biomasa de la segunda etapa. En la primera etapa se usara un reactor anaerobio de lotes secuencial, en la segunda se usara un reactor aerobio en lote secuencial utilizando condiciones dinámicas de ciclo de alimentación y reposo, y por último en el tercer paso utilizaremos un reactor de alimentación por pulsos, donde una cantidad de sustrato proveniente del paso uno es añadido secuencialmente hasta obtener el máximo contenido intracelular de PHA dentro del microorganismo.

\section{Materiales y Métodos}

\subsection{Diseño de experimento}

El experimento consistió en un sistema de tres reactores a escala de laboratorio. La etapa 1 consistió en una fermentación acidogénica del suero de quesería llevada a cabo en un reactor de lote secuencial operado bajo condiciones anaeróbicas. El efluente de este reactor fue posteriormente clarificado por filtración y usado como alimentación en un reactor aerobio para la selección del cultivo microbiano llevado a cabo en un reactor de lote secuencial sujeto a condiciones de alimentación aeróbica dinámica. La etapa 3 fue llevada a cabo usando el efluente de la etapa 1en un reactor de lote alimentado usando el inoculo desarrollado en la etapa 2 para obtener la máxima cantidad de PHA por contenido seco de biomasa activa.

\subsection{Reactor anaerobio de lote secuencial}

El reactor anaerobio de lote secuencial es un proceso de acidogénesis para el tratamiento de aguas residuales el cual trabaja por ciclos. Cada ciclo está formado de 4 etapas: llenado, reacción y agitación, decantación y vaciado con remoción de lodo cuando sea necesario para evitar procesos de metanización a través del manejo de los tiempos de retención hidráulica independiente de los tiempos de retención de sólidos.

Para este experimento se utilizó un reactor de $3 \mathrm{~L}$ mantenido a $35^{\circ} \mathrm{C}$ por acción de una manta térmica, se utilizó bombas peristálticas controladas por temporizadores para el control de alimentación, vaciado y control de $\mathrm{pH}$ el cual debía estar regulado a 6 bajo la acción de adición de $\mathrm{NaOH} 0.6$ N. El tiempo de retención hidráulica TRH fue de 2 días y el tiempo de retención de solidos TRS fue de 15 días. La velocidad de carga orgánica fue de $4.3 \mathrm{mg} / \mathrm{L}$. El reactor se ha mantenido en funcionamiento por 107 días desde el inicio del experimento.

El volumen de carga inicial fue de 2 litros, como inoculo se utilizó biomasa proveniente de laboratorio.
Para la alimentación del reactor se utilizó una dilución de 1/5 del efluente del agua de suero completando con agua sintética que contiene $10 \mathrm{mmol}$ de $\mathrm{N}$ y $4 \mathrm{mmol}$ de P. La velocidad de carga orgánica es:

$$
\mathrm{VCO}=4.3 \mathrm{gDQOl} /
$$

Las condiciones del reactor de lote secuencial anaerobio fueron:
Alimentación 10 minutos
Reacción 11 horas
Decantación 40 minutos
Vaciado 10 minutos.

Los productos de la fermentación anaerobia fueron mayoritariamente acidos grasos volátiles AGV (acetato, propionato, butirato y valerato) hace cerca del $75 \%$ del DQO presente en el efluente fermentado. La conversión de azucares $-\mathrm{AGV}$ fue de $0.70 \mathrm{Cmol}$ AGV/ Cmol azúcar.

El efluente fue retirado por vaciado y colectado en un tanque refrigerado a $4^{\circ} \mathrm{C}$ para posteriormente ser filtrado. El efluente clarificado se mantuvo a $4^{\circ} \mathrm{C}$ previo su uso como sustrato en el reactor aerobio para enriquecimiento de cultivos mixtos.

\subsection{Reactor para la selección de cultivos acumuladores de PHAs.}

Reactor de lote secuencial.- Se utilizó un bioreactor de doble camisa de vidrio con un volumen de trabajo de $1 \mathrm{~L}$ para el cultivo de bacterias productoras de PHA. El reactor fue equipado con un agitador eléctrico de 4 palas y regulado térmicamente a $35^{\circ}$ en un baño de agua. Se utilizaron bombas peristálticas con temporizadores para utilizarlos en el llenado, vaciado y tiempo de agitación del reactor.

El RLS (reactor de lote secuencial) fue inoculado con cultivos microbianos con capacidad de acumular PHA. El reactor trabaja en condiciones dinámicas aeróbicas de alimentación en ciclos de $12 \mathrm{~h}$ compuesto de 4 periodos: 2 min de llenado, aeración (alimentación y reposo) 11h, decantación 30 min y vaciado $5 \mathrm{~min}$.

El tiempo de retención Hidráulica se mantuvo en 1 día. El tiempo de retención de solidos se mantuvo en 10 días realizando una purga diaria del reactor agitado.

El reactor se alimentó con una mezcla del efluente obtenido de la fermentación en el reactor anaerobio de la etapa 1 y agua sintética que contiene nutrientes y ácidos grasos volátiles completando una concentración de $80 \mathrm{Cmmol} \mathrm{AGV} / \mathrm{L}$. La relación C/N/P fue 80/4/1 La solución de alimentación se mantuvo a $4^{\circ} \mathrm{C} .500 \mathrm{ml}$ de la solución de alimentación se bombea dentro del reactor en el comienzo de cada ciclo usando la bomba peristáltica. Tiourea se 
adiciono a la solución mineral para inhibir la nitrificación. Una segunda bomba peristáltica se usó para retirar el efluente del reactor aproximadamente $500 \mathrm{ml}$ por ciclo después de una fase de reposo o decantación. Se administró aire a través de un difusor de pecera. La agitación se mantuvo en alrededor de $500 \mathrm{rpm}$. El pH se mantuvo sin control durante la fase de reacción.

\subsection{Reactor para la producción de PHAs.}

Los ensayos de acumulación de PHAs fue llevado a cabo en un reactor de $2 \mathrm{~L}$ con un volumen inicial de trabajo de $500 \mathrm{ml}$ operando en modo continuo, inoculado con un cultivo proveniente del paso dos del reactor de lote secuencial el cual fue colectado al final de la fase de reposo, y alimentado como el efluente clarificado fermentado producido de la etapa 1 . La acumulación de PHA se llevó sin adición extra de amonio o fosfato adicional. La aeración se mantuvo en $400 \mathrm{ml} / \mathrm{min}$ y la agitación a $300 \mathrm{rpm}$. El reactor se mantuvo en una temperatura de $30^{\circ} \mathrm{C}$ y la aeración continua a través de un difusor de pecera.

El efecto de alimentación utilizando un control de pH se realizó en un ensayo A y con control de consumo de oxigeno por pulsos en un ensayo B. tanto en el ensayo A y B se adiciono del efluente de la etapa 1 con concentración de AGV de 150 - 160 Cmmol/L.

En el ensayo A fue operado con control de $\mathrm{pH}$ entre 8.8 y 8.5 en este caso el inicio del pH se usó como un medio de control en la adición de sustrato en el reactor, lo que la alimentación rico en AGV fue usado con solución acida para el control de pH.

En el ensayo B se adiciono 4 pulsos de $60 \mathrm{ml} 80 \mathrm{ml}$ $100 \mathrm{ml}$ y $140 \mathrm{ml}$ manteniendo el control de consumo de oxigeno de la solución alimentadora inicial. Los AGV en el efluente son acetato, propionato, butirato y valerato $(61 / 25 / 12 / 2)$.

\subsection{Procedimientos analíticos.}

La concentración de la biomasa fue determinada usando el procedimiento descrito en "Standard Methods" (APHA, 1995) para solidos suspendidos volátiles SSV y solidos suspendidos totales SST.

Las concentraciones de ácidos grasos volátiles fueron determinados por cromatografía liquida de alto rendimiento (HPLC) usando un cromatógrafo Hewlett Packard serie 1100 (USA), se utilizó Ácido fosfórico $0.1 \%$ se utilizó como eluente. La concentración de ácidos orgánicos fue calculada a través de curvas de calibración usando utilizando reactivos estándar (grado analítico Merck).
La concentración de polihidroxialcanoato fue determinado por cromatografía de gases utilizando el método adaptado por Serafim y colaboradores (2004). Donde la masa liofilizada fue incubada por metanólisis en cloroformo y un $20 \%$ de ácido sulfúrico en solución de metanol. Después del periodo de digestión la fase orgánica (monómeros metilados disueltos en cloroformo) de cada muestra fue extraído e inyectada dentro del cromatógrafo de gas Focus GC. La columna fue usada a una tasa de flujo de $2 \mathrm{ml} / \mathrm{min}$. El split ratio fué de 5 a $280^{\circ} \mathrm{C}$. La temperatura del horno fue como sigue $40^{\circ} \mathrm{C}$ luego $30^{\circ} \mathrm{C} / \mathrm{min}$ hasta los $50^{\circ} \mathrm{C}$ entonces $8^{\circ} \mathrm{C} / \mathrm{min}$ hasta los $160^{\circ} \mathrm{C}$ y finalmente $50^{\circ} \mathrm{C}$ hasta los $220^{\circ} \mathrm{C}$ el detector de temperatura fue colocado a $250 \quad{ }^{\circ} \mathrm{C}$. La concentración de hidroxibutirato e hidroxivalerato fue calculado utilizando dos curvas de calibración una para hidroxivalerato y otra para hidroxivaleratoutilizando estándar (0.1 -2mg/ml) de P (HA-HB) comercial (88\% 112\%) (Sigma) y corregido usando heptadecano interno estándar (concentración de aproximadamente de $1 \mathrm{mg} / \mathrm{ml})$.

\section{Resultados y discusión.}

\subsection{Reactor acidogénico: producción de AGV.}

Se utilizó un reactor de capacidad de 3 litros y se procedió con un volumen de carga de 2 litros. Se utilizó una mezcla de suero de quesería con agua destilada en dilución 1:5. El suero contiene: Azucares totales: 29.9 g/L; DQO: 42,700 g/l; Nitrógeno Total: $66.7 \mathrm{mg} / \mathrm{l}$; SST: $1.25 \mathrm{~g} / \mathrm{l}$; SSV: $1.05 \mathrm{~g} / \mathrm{l} ; \mathrm{pH}$ : 6.00; fosfato: $1.16 \mathrm{mg} / \mathrm{l}$. Como inoculo se utilizó biomasa proveniente de laboratorio. El tiempo de retención hidráulica fue de 48 horas, y el tiempo de retención de solidos: 15 días; la temperatura se mantuvo en los $30^{\circ}$ $\mathrm{C}$ con un control de $\mathrm{pH}$ : 5.9 - 6.1. Se adicionó la cantidad suficiente de amonio para tener un total de $5 \mathrm{mmol}$ de $\mathrm{N}-\mathrm{NH}_{4}$ y $1 \mathrm{mmol}$ de $\mathrm{P}$ además se utilizó $\mathrm{NaOH} 6 \mathrm{~N}$ para estabilizar el $\mathrm{pH}$ a 6 .

El volumen de carga orgánica fue igual a $\mathrm{VCO}=$ 4.3gDQOl/d.

Condiciones del reactor SBR anaerobio fue:

Alimentación 10 minutos

Reacción 11 horas

Decantación 40 minutos

Vaciado 10 minutos.

Los resultados del reactor acidogénico se muestra en la figura 1, mostrando que el porcentaje de formación:

HAc :HPr: HBu: HVal = 


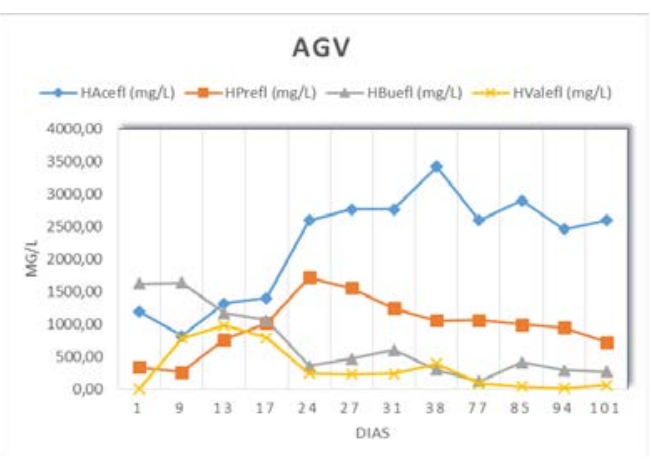

Figura 1. Formación de AGV en el reactor acidogénico

La evolución del proceso de fermentación en un lapso de poco más de tres meses dio como resultado que el $74 \%$ total de DQO (demanda química de oxígeno) perteneciente mayoritariamente a azucares proveniente de la lactosa se transforma en ácidos grasos volátiles (AGV) mientras que un $12 \%$ podría sufrir formación en hidrogeno $\quad \mathrm{O}^{\mathrm{CH}_{4}}$ debido a presencia de metanización del proceso anaeróbico (fig. 2). Existe también la probabilidad de formación de ácidos grasos de cadenas largas que se podrían entender por el DQO en el efluente que no correspondería con la totalidad de DQO correspondiente a la formación de ácidos grasos volátiles efluente.

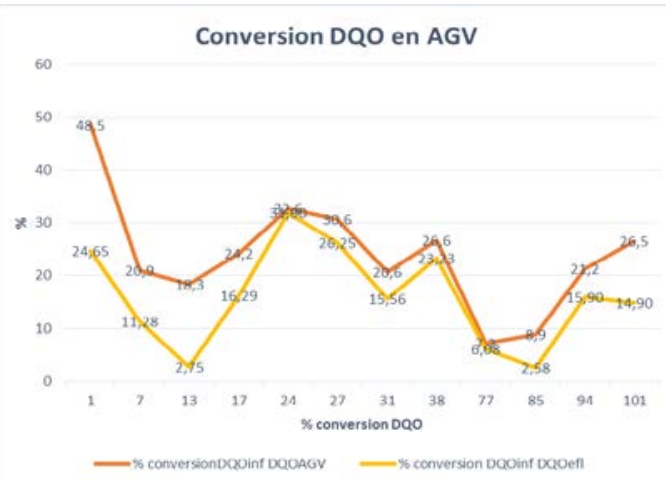

Figura 2 Porcentaje de formación de AGV

\subsection{Enriquecimiento de cultivos productores de PHAs.}

La figura 3 muestra el funcionamiento del reactor de lote secuencial el cual se obtuvo después de dos meses de operación y selección de las cepas bacterianas capaces de acumular polihidroxialcanoato utilizando condiciones dinámicas de alimentación con ciclos de alimentación y reposo.

El efluente de alimentación que se utilizó fue el obtenido en la fase uno del reactor acidogénico diluido permitiendo que la biomasa se desarrolle con capacidad máxima de almacenamiento de PHAs, permitiendo a su vez evitar que parte del sustrato que no pertenece a $A G V$ no entorpezca el proceso de selección de cepas acumuladoras de PHAs. Por tal motivo se utilizó una dilución 1:4 de efluente del reactor 1 con agua sintética adicionada con AGV simulando el agua real.

El contenido de Amonio es otro factor importante en el tratamiento de agua residual como sustrato para la acumulación de PHA debido en gran medida a que la proporción adicionada de Amonio medida como Nmmol en comparación con la cantidad de carbono adicionado como Cmmol debe estar en la relación tal que permita la acumulación de PHA y evite el crecimiento excesivo de la biomasa en una relación comparable. Otro nutriente importante a tomar en consideración es el fosfato presente en el agua que sirve como sustrato. Algunos investigadores consideran que la relación 100:2:1 para carbono: amonio: fosfato seria idónea para propiciar el almacenaje de PHA sin propiciar excesivamente el crecimiento de la biomasa activa.

Otros parámetros a considerar cuidadosamente son el tiempo de retención hidráulico (TRH) que es el tiempo suficiente que permanece el influente en el reactor para procesar toda la carga orgánica. El tiempo de retención de solidos (TRS) que se considera como el tiempo que permanece el lodo activo dentro del reactor. El TRS es un importante parámetro a considerar por cuanto puede incidir en la acumulación excesiva de biomasa o formación de microorganismos ajenos al propósito de acumulación de PHAs.

Las condiciones dinámicas de acumulación de PHA consiste en etapas de alimentación y de reposo para lo cual se agrega un pulso inicial de sustrato en el cual se mide el tiempo en el cual los microorganismos consumen todo los AGV seguido de una etapa de reposo en el cual los microorganismos utilizan el almacén de PHA para sobrevivir el tiempo en el que no son alimentados.

En el experimento desarrollado se muestra que el tiempo de alimentación fue de aproximadamente 90 min a partir de ahí se inicia el proceso de reposo que se mantuvo en 10 horas.

Este proceso es importante para la selección de las bacterias capaces de acumular polihydroxialcanoatos y a su vez descartar a aquellas que no debido a un tiempo de reposos lo suficientemente largo para ir descartando cepas que pudieran interferir con las adecuadas. En nuestro estudio según la figura 5 se muestra la población capaz de procesar sustratos de AGV y convertirla en PHAs. Los estudios anteriores han demostrado que las cepas cubren un amplio espectro desde Esherichia coli, Pseudomonas, Ralstonias, espiroquetas, cocos etc. 


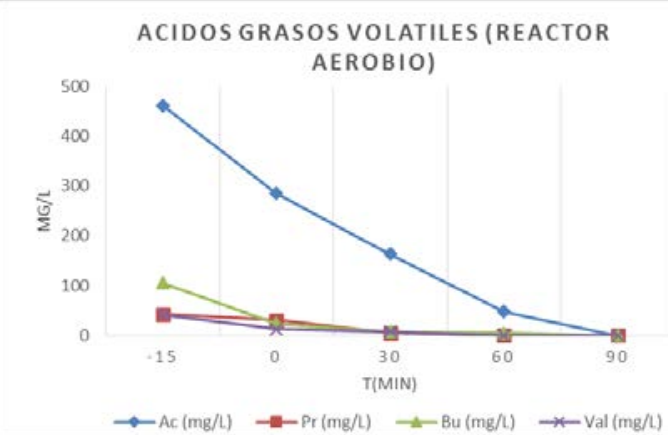

Figura 3. Efecto de alimentación en el reactor aerobio de AGV.

\subsection{Producción de PHAs.}

El potencial de la población microbiana para acumular grandes cantidades de PHA se evaluó en un reactor de alimentación utilizando un control de $\mathrm{pH}$ con el efluente del reactor acidogénico y su contenido de ácidos grasos volátiles limitando el crecimiento de la biomasa al limitar el contenido de amonio a una relación de Cmmol/Nmmol 50:1 respectivamente. El cultivo fue capaz de alcanzar un contenido de PHA de $42 \%$ dentro de las 8 horas según la figura 4 utilizando el sistema de pulsos, lo que para este estudio se utilizo cuatro pulsos de una concentración inicial del sustrato de $80 \mathrm{Cmmol}$ de AGV como sustrato, para lo cual se adicionó un primer pulso de $60 \mathrm{ml}$ uno segundo de 80 $\mathrm{ml}$, el tercero de $100 \mathrm{y}$ el ultimo de $140 \mathrm{ml}$ midiendo con el sensor de Oxigeno el momento en que los valores de este aumenten abruptamente dando constancia que la alimentación ha cesado.

En otros dos experimentos se usó el control directo de un sensor de $\mathrm{pH}$ conociendo que los valores de esto varían desde un 8.4 a un 8.9 se fijo estos valores para que mediante una bomba peristáltica adicione una cantidad determinada de sustrato de concentración conocida (160 y 1000Cmmol) cuando los valores de $\mathrm{pH}$ suban al limite superior indicando que los AGV han sido consumidos en su gran mayoría.

Según los resultados mostrados en la tabla 1 donde se muestra que la adición de sustrato en altas concentraciones podrían dar como resultado una mejor performance y capacidad de ahorro de PHA.

Además se podría demostrar que un método de obtención de PHA usando un medidor de $\mathrm{pH}$ sería un método mucho más factible por la comodidad y facilidad del proceso, debido a que no necesita del control manual y la adición de sustrato cuando los niveles de consumo de oxígeno aumenten.

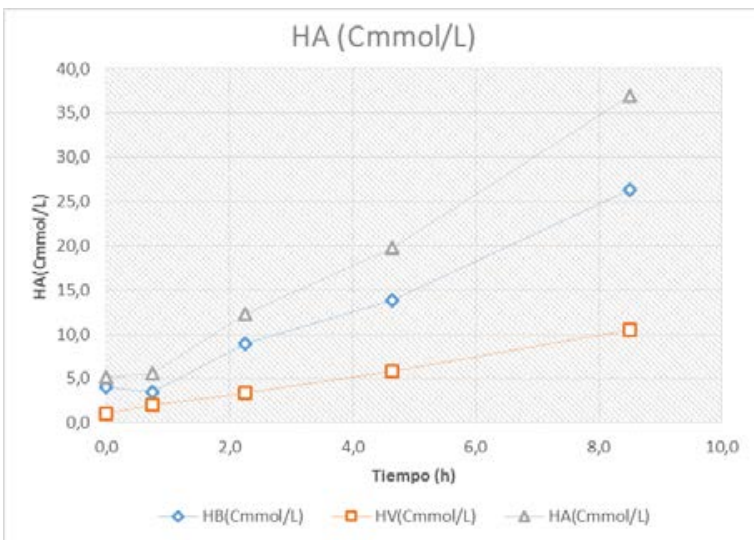

Figura 4. Porcentaje de acumulación de PHA en reactor de alimentación.

Tabla 1. Parámetros de producción de PHA como función de régimen de alimentación.

\begin{tabular}{|c|c|c|c|}
\cline { 2 - 4 } \multicolumn{1}{c|}{} & \multicolumn{3}{c|}{ Parámetros } \\
\hline Alimentación & $\begin{array}{c}\text { Sustrato } \\
\text { (Cmmol } \\
\text { AGV/L) }\end{array}$ & PHA \% & $\begin{array}{c}\text { PHA } \\
\text { (\% } \mathbf{H B}: \mathbf{H V})\end{array}$ \\
\hline A1 pulso & 80 & 43 & $70: 30$ \\
\hline B1continuo & 160 & 33 & $75: 25$ \\
\hline B2 continuo & 1000 & 44 & $72: 28$ \\
\hline
\end{tabular}

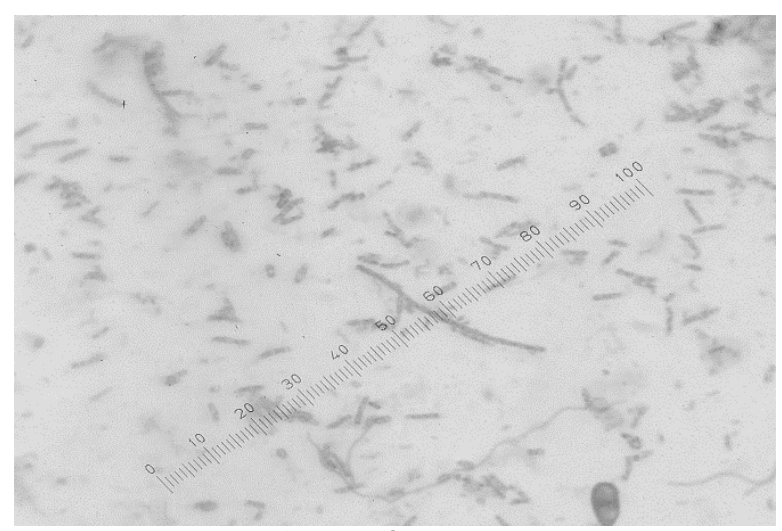

Figura 5. Microfotografía del cultivo bacteriano en la biomasa del reactor.

\section{Conclusiones y perspectivas}

Las estrategias para mejorar la productividad de PHA en base a un proceso de tres etapas a partir de suero lácteo. Hemos encontrado que el uso de una alimentación continua en base a un control de $\mathrm{pH}$ no solamente ayuda al proceso mucho más engorroso de utilizar alimentación por pulsos. También permite grandes tasas de retoma de sustrato y almacenaje de polímero.

Es necesario encontrar un proceso que pueda mejorar la producción de PHA abaratando costos con 
relación a los obtenidos de la industria petroquímica; debido a que la eficiente producción de poliésteres depende altamente del costo del sustrato usado aquí en este trabajo se muestra como residuos de industrias como la láctea podrían otorgar sustratos baratos para la producción sostenible de ácidos grasos volátiles y a su vez de polihidroxialcanoatos.

En este trabajo muestra que el uso de efluentes de agua de quesería para la producción de PHA es posible, aunque se necesitan más estudios para determinar que cepas de microorganismos pueden ser más efectivas en el almacén intracelular del biopolímero, futuros estudios para el aislamiento de la cepa serán necesarios para mejora del método en los tiempos de las condiciones dinámicas de alimentación.

\section{Agradecimientos}

-Beca otorgada para estudios de posgrado otorgado por SENESCYT-Ecuador (Convocatoria Abierta 2012).

-Agradecimiento especial al financiamiento parcial a la "Universidad Estatal Península de Santa Elena”para el desarrollo de esta investigación.

-Agradecimiento al Laboratorio de Ingeniería Química de la Universidad de la Coruña, España por las facilidades de instalaciones y desarrollo de los experimentos.

\section{Referencias}

[1] Albuquerque, M. G. E., Eiroa, M., Torres, C., Nunes, B. R., \& Reis, M. a M. (2007). Strategies for the development of a side stream process for polyhydroxyalkanoate (PHA) production from sugar cane molasses. Journal of Biotechnology, 130(4), 411-21. doi:10.1016/j. jbiotec. 2007. 05. 011

[2] Albuquerque, M. G. E., Martino, V., Pollet, E., Avérous, L., \& Reis, M. a M. (2011). Mixed culture polyhydroxyalkanoate (PHA) production from volatile fatty acid (VFA)-rich streams: effect of substrate composition and feeding regime on PHA productivity, composition and properties. Journal of Biotechnology, 151(1), 66-76. doi:10.1016/j.jbiotec.2010.10.070

[3] Demirel, B., Yenigun, O., \& Onay, T. T. (2005). Anaerobic treatment of dairy wastewaters: a review. Process Biochemistry, 40(8), 25832595. doi:10.1016/j.procbio.2004.12.015.
[4] Bosco, F., \& Chiampo, F. (2010). Production of polyhydroxyalcanoates (PHAs) using milk whey and dairy wastewater activated sludge production of bioplastics using dairy residues. Journal of Bioscience and Bioengineering, 109(4), 418-21. doi:10.1016/j.jbiosc.2009.10.012

[5] Chakravarty, P., Mhaisalkar, V., \& Chakrabarti, T. (2010). Study on poly-hydroxyalkanoate (PHA) production in pilot scale continuous mode wastewater treatment system. Bioresource Technology, 101(8), 2896-9. doi:10.1016/ j. biortech. 2009.11.097

[6] Demirel, B., \& Yenigun, O. (2004). Anaerobic acidogenesis of dairy wastewater: the effects of variations in hydraulic retention time with no pH control. Journal of Chemical Technology \& Biotechnology, 79(7), 755-760. doi: 10.1002 /jctb.1052

[7] Demirel, B., Yenigun, O., \& Onay, T. T. (2005). Anaerobic treatment of dairy wastewaters: a review. Process Biochemistry, 40(8), 25832595. doi:10.1016/j.procbio.2004.12.015

[8] García, Y. G., Carlos, J., Contreras, M., Reynoso, O. G., \& Córdova, A. (2013). (Recibido diciembre 2011, aceptado noviembre 2012), 29(1), 77-115.

[9] Johnson, K., Kleerebezem, R., \& van Loosdrecht, M. C. M. (2010). Influence of the $\mathrm{C} / \mathrm{N}$ ratio on the performance of polyhydroxybutyrate (PHB) producing sequencing batch reactors at short SRTs. Water Research, 44(7), 2141-52. doi:10.1016/j.watres.2009.12.031

[10] Lemos, P. C., Serafim, L. S., \& Reis, M. a M. (2006). Synthesis of polyhydroxyalkanoates from different short-chain fatty acids by mixed cultures submitted to aerobic dynamic feeding. Journal of Biotechnology, 122(2), 226-38. doi:10.1016/j.jbiotec.2005.09.006

[11] Lemos, P. C., Viana, C., Salgueiro, E. N., Ramos, A. M., Crespo, J. P. S. G., \& Reis, M. A. M. (1998). Effect of carbon source on the formation of polyhydroxyalkanoates ( PHA ) by a phosphate-accumulating mixed culture, 0229(97), 662-671.

[12] Reis, M. a M., Serafim, L. S., Lemos, P. C., Ramos, a M., Aguiar, F. R., \& Van Loosdrecht, M. C. M. (2003). Production of polyhydroxyalkanoates by mixed microbial cultures. Bioprocess and Biosystems 
Engineering, 25(6), 377-85. doi: 10. 1007 /s00449-003-0322-4

[13] Salehizadeh, H., \& Van Loosdrecht, M. C. M. (2004). Production of polyhydroxyalkanoates by mixed culture: recent trends and biotechnological importance. Biotechnology Advances, 22(3), 261-279. doi:10.1016/j.biotechadv.2003.09.003

[14] Yang, K., Yu, Y., \& Hwang, S. (2003). Selective optimization in thermophilic acidogenesis of cheese-whey wastewater to acetic and butyric acids: partial acidification and methanation. Water Research, 37(10), 2467-77. doi:10.1016/S0043-1354(03)00006-X 